\title{
MENENTUKAN CADANGAN PREMI ASURANSI KESEHATAN INDIVIDU PERAWATAN RUMAH SAKIT MENGGUNAKAN METODE RETROSPEKTIF
}

\author{
Mirawati I. P. Hetharie ${ }^{1}$, Lexy J. Sinay ${ }^{2}$, Marlon. S. Noya van Delsen ${ }^{3}$ \\ 1,2,3 Jurusan Matematika Fakultas Matematika dan Ilmu Pengetahuan Alam, Universitas Pattimura \\ Jln. Ir. M. Putuhena, Kampus Unpatti, Poka-Ambon, Indonesia \\ e-mail: ${ }^{1}$ mira.hetharie08@gmail.com; ${ }^{2}$ lexyjz@gmail.com; ${ }^{3}$ marlonnvd@gmail.com
}

\begin{abstract}
Abstrak
Asuransi kesehatan individu perawatan rumah sakit merupakan asuransi yang memberikan santunan kesehatan kepada pihak tertanggung untuk membiayai pengobatan dan perawatan rumah sakit apabila ia terserang penyakit. Dari premi yang dibayarkan pihak tertanggung, perusahaan akan mengelolanya untuk mendanai biaya kesehatan dari pihak tertanggung. Perusahaan asuransi juga wajib mengelola cadangan preminya untuk menghindari terjadinya kerugian akibat klaim sebelum jatuh tempo. Perhitungan cadangan premi pada asuransi ini menggunakan metode retrospektif yang berorientasi pada pengeluaran di waktu lampau. Untuk menghitung cadangan premi terlebih dahulu dihitung premi bersih tahunan yang diperuntukan untuk keluarga yang terdiri dari ayah, ibu dan anak dengan menggunakan tabel CSO 1941 suku bunga 2,5\%. Besarnya premi bersih tahunan semakin meningkat setiap tahunnya begitu pula dengan cadangan premi asuransi dengan lama masa pertanggungan selama 10 tahun.
\end{abstract}

Kata Kunci: Asuransi kesehatan, Asuransi perawatan rumah sakit, Cadangan premi, Cadangan retrospektif

\section{DETERMINE THE RESERVE OF INDIVIDUAL HEALTH INSURANCE PREMIUMS OF HOSPITAL CARE USING RETROSPECTIVE METHOD}

\begin{abstract}
Individual health insurance hospital care is an insurance that provides health benefits to the insured party to finance the treatment and hospital care if he had the disease. Of the premiums paid by the insured, the company will manage it to fund the health costs of the insured. Insurance companies are also required to manage their premium reserves to avoid any claim losses before they mature. The calculation of premium reserves on this insurance uses a retrospective method that is oriented to spending in the past. To calculate the premium reserve, it is calculated the annual net premium for the family consisting of father, mother and child using table CSO 1941 interest rate 2.5\%. The annual net premiums are increasing every year as well as the insurance premium reserves with a 10 -year coverage period.
\end{abstract}

Keywords: Health insurance, Hospital care insurance, Premium reserves, Retrospective reserves

\section{Pendahuluan}

Resiko terserang suatu penyakit maupun kecelakaan pasti dialami oleh setiap orang dan tidak seorang pun dapat mengetahui kapan penyakit tersebut maupun musibah tersebut akan datang. Tak jarang penyakit atau kecelakaan tersebut menyebabkan seseorang harus mendapatkan pengobatan dan perawatan di rumah sakit. Dengan biaya rumah sakit sekarang yang semakin meningkat, pasti akan menjadi masalah besar bagi mereka yang mempunyai penghasilan tidak mencukupi. Untuk mengatasi masalah tersebut diperlukan asuransi kesehatan. 
Asuransi kesehatan merupakan suatu alat keuangan yang menyediakan dana untuk biaya perawatan rumah sakit anggota asuransi dan keluarganya selama ia tak mampu bekerja [1]. Melalui asuransi kesehatan maka biaya pengobatan dan perawatan rumah sakit yang ditanggung oleh seseorang akan diganti oleh pihak asuransi. Asuransi kesehatan perawatan rumah sakit merupakan asuransi yang memberikan santunan kesehatan kepada pihak tertanggung berupa sejumlah uang untuk membiayai pengobatan dan perawatan bila ia diserang penyakit di luar kehendaknya [5]. Imbalan atas santunan kesehatan yang diberikan oleh perusahaan asuransi maka tertanggung wajib membayar premi kepada perusahaan, pada umumnya dibayar secara berkala, misal bulanan, triwulan, semester atau tahunan.

Tidak sedikit perusahaan asuransi mengalami kerugian dikarenakan perusahaan tersebut belum tepat dalam mengatur cadangan premi asuransinya. Akibatnya, perusahaan asuransi tersebut tidak mampu membayar uang pertanggungan kepada pihak tertanggung pada saat terjadi klaim sebelum jatuh tempo. Keadaan ini dapat diantisipasi dengan menentukan cadangan premi yang tepat. Untuk menghitung dana cadangan bersih setiap tahunnya maka perusahaan asuransi harus menghitung premi bersih setiap tahunnya yang belum dijumlahkan dengan biaya operasional [3]. Perhitungan cadangan premi asuransi secara umum ada 2, yaitu cadangan retrospektif dan cadangan prospektif [2]. Cadangan retrospektif merupakan cadangan asuransi yang perhitungannya berorientasi pada pengeluaran di waktu lampau. Sedangkan cadangan prospektif merupakan cadangan asuransi yang perhitungannya berorientasi pada pengeluaran di waktu yang akan datang (Sembiring, 1986). Penelitian ini bertujuan untuk menentukan besarnya premi tahunan dan cadangan premi dengan menggunakan metode retrospektif.

\section{Landasan Teori}

\subsection{Asuransi Jiwa}

Beberapa simbol yang digunakan pada perhitungan asuransi jiwa antara lain :

- $\quad l_{x}$ adalah jumlah orang hidup usia tepat $x$ tahun

- $d_{x}$ adalah jumlah orang yang meninggal antara usia $x$ dan $x+1$ tahun, $d_{x}=l_{x}-l_{x+1}$

- ${ }_{n} p_{x}$ adalah peluang seseorang yang berusia $x$ tahun akan hidup mencapai usia $x+n$ tahun, dengan, ${ }_{n} p_{x}=\frac{l_{x+n}}{l_{x}}$

- ${ }_{n} q_{x}$ adalah peluang seseorang yang berusia $x$ tahun akan meninggal sebelum $x+n$ tahun

Sedangkan beberapa simbol komutasi yang diperlukan untuk mempermudah perhitungan adalah

$$
\begin{aligned}
& D_{x}=v^{x} l_{x} \\
& N_{x}=D_{x}+D_{x+1}+D_{x+2}+\ldots+D_{\omega}=\sum_{i=0} D_{x+i} \\
& S_{x}=N_{x}+N_{x+1}+N_{x+2}+\ldots+N_{\omega}=\sum_{i=0} N_{x+i} \\
& C_{x}=v^{x+1} d_{x} \\
& M_{x}=C_{x}+C_{x+1}+C_{x+2}+\ldots+C_{\omega}=\sum_{i=0} C_{x+i} \\
& R_{x}=M_{x}+M_{x+1}+M_{x+2}+\ldots+M_{\omega}=\sum_{i=0} M_{x+i}
\end{aligned}
$$

Dengan : $x=$ usia (tahun),$v=\frac{1}{1+i}=(1+i)^{-1}$

Dengan $i$ merupakan tingkat bunga dalam setahun, dan $\omega$ merupakan usia tertinggi yang dicapai.

Dalam asuransi jiwa pembayaran premi biasanya dilakukan secara berkala. Pembayaran secara berkala disini dinamakan anuitas. Anuitas yang sering digunakan adalah anuitas berjangka dan anuitas seumur hidup.

Anuitas berjangka adalah pembayaran berkala dalam jangka waktu tertentu, misal $\mathrm{n}$ tahun. 


$$
\ddot{a}_{\overline{x: n}}=\frac{N_{x}-N_{x+1}}{D_{x}}
$$

Anuitas seumur hidup adalah pembayaran berkala selama orang tersebut masih hidup

$$
\ddot{a}_{x}=\frac{N_{x}}{D_{x}}
$$

Untuk membayar berapa besar santunan yang harus dibayarkan perusahaan asuransi kepada ahli waris digunakan perumusan:

Asuransi seumur hidup, yaitu asuransi yang memberikan santunan kepada ahli waris kapanpun tertanggung meninggal, maka premi tunggal bersihnya adalah:

$$
A_{x}=\frac{M_{x}}{D_{x}}
$$

Asuransi berjangka, yaitu asuransi yang memberikan santunan kepada ahli waris apabila tertanggung meninggal dalam jangka waktu, misal $n$ tahun, maka premi tunggal bersihnya adalah:

$$
A_{x: n}=\frac{M_{x}-M_{x+n}}{D_{x}}
$$

Sehingga untuk pembayaran premi bersih secara berkala (bulanan, triwulan, semester atau tahunan) digunakan rumusan dasar sebagai berikut :

$$
\begin{aligned}
\text { Nilai Premi } & =\text { Nilai Santunan } \\
P \ddot{a} & =A
\end{aligned}
$$

\subsection{Asuransi Kesehatan}

Misal usia tertanggung $x$ tahun, apabila selama satu tahun ini kemungkinan dirawat dirumah sakit adalah $q_{x}^{\text {sh }}$, rata-rata jumlah hari perawatan rumah sakit $T^{\text {sh }}$ maka memperoleh benefit harian di rumah sakit sebesar 1 satuan, 1 tahun kemudian kemungkinan dirawat dirumah sakit adalah $q_{x+1}{ }^{\text {sh }}$, kemungkinan hidup adalah ${ }_{1} p_{x}$, dan rata-rata jumlah hari perawatan rumah sakit $T^{\text {sh }}$ maka memperoleh benefit harian di rumah sakit sebesar 1 satuan. 2 tahun kemudian kemungkinan dirawat dirumah sakit adalah $q_{x+2}{ }^{\text {sh }}$, kemungkinan hidup ${ }_{2} p_{x}$, ratarata jumlah hari perawatan rumah sakit $T^{\text {sh }}$ maka memperoleh benefit harian di rumah sakit sebesar 1 satuan, dan seterusnya samapai jangka waktu yang dikehendaki, missal $n$ tahun [6].

Jadi premi tunggal bersih asuransi kesehatan individu perawatan rumah sakit adalah :

$$
\begin{aligned}
& =v^{\frac{1}{2}} q_{x}^{s h} T^{s h}+v^{1+\frac{1}{2}}{ }_{1} p_{x} q_{x+1}^{s h} T^{s h}+v^{2+\frac{1}{2}}{ }_{2} p_{x} q_{x+2}^{s h} T^{s h}+\ldots+v^{(n-1)+\frac{1}{2}}{ }_{(n-1)} p_{x} q_{x+(n-1)}^{s h} T^{s h} \\
& =T^{s h}\left(v^{\frac{1}{2}} q_{x}^{s h}+v^{1+\frac{1}{2}}{ }_{1} p_{x} q_{x+1}^{s h}+v^{2+\frac{1}{2}}{ }_{2} p_{x} q_{x+2}^{s h}+\ldots+v^{(n-1)+\frac{1}{2}}{ }_{(n-1)} p_{x} q_{x+(n-1)}^{s h}\right) \\
& =T^{s h} \sum_{t=0}^{n-1} v^{t+\frac{1}{2}}{ }_{t} p_{x} q_{x+t}^{s h}
\end{aligned}
$$

Jika preminya adalah tahunan, maka secara rumus dapat dinyatakan sebagai $P \ddot{a}=A$. 


$$
\begin{aligned}
P \ddot{a}_{x: n} & =T^{s h} \sum_{t=0}^{n-1} v^{t+\frac{1}{2}}{ }_{t} p_{x} q_{x+t}^{s h} \\
P & =\frac{T^{s h} \sum_{t=0}^{n-1} v^{t+\frac{1}{2}} \frac{l_{x+t}}{l_{x}} q_{x+t}^{s h}}{\frac{N_{x}-N_{x+n}}{D_{x}}} \\
P & =\frac{T^{s h} \sum_{t=0}^{n-1} v^{t+\frac{1}{2}} \frac{l_{x+t}}{l_{x}} q_{x+t}^{s h} D_{x}}{N_{x}-N_{x+n}} \\
P \quad & \frac{T^{s h} \sum_{t=0}^{n-1} v^{x+t+\frac{1}{2}} l_{x+t} q_{x+t}^{s h}}{N_{x}-N_{x+n}} \\
P \quad= & \frac{T^{s h} \sum_{t=0}^{n-1} \bar{D}_{x+t} q_{x+t}^{s h}}{N_{x}-N_{x+n}}
\end{aligned}
$$

\subsection{Cadangan Retrospektif}

Secara umum, perhitungan cadangan premi asuransi terbagi atas 2 yaitu cadangan retrospektif dan cadangan prospektif [2]. Cadangan retrospektif merupakan cadangan yang berorientasi pada pengeluaran di waktu lampau. Sedangkan cadangan prospektif merupakan cadangan yang berorientasi pada pengeluaran di waktu yang akan datang [4].

Formula yang diguanakan dalam perhitungan cadangan premi tahunan pada asuransi kesehatan perawatan rumah sakit adalah sebagai berikut :

Cadangan retrospektif pada akhir tahun pertama [4]: ${ }_{1} V=\frac{l_{x} \cdot P(1+i)-d_{x}}{l_{x+1}}$

Dengan :

${ }_{1} V \quad$ : cadangan pada akhir tahun pertama

$l_{x} \quad:$ jumlah orang yang hidup pada usia $x$ tahun

$P(1+i) \quad$ : premi yang dibayarkan pada permulaan tahun pertama dan dibungakan selama setahun

$d_{x} \quad$ : banyaknya orang berusia $x$ yang meninggal dalam satu tahun

$l_{x+1} \quad$ : banyaknya orang berusia $x$ tahun yang hidup satu tahun kemudian

Cadangan pada akhir tahun kedua : ${ }_{2} V=\frac{\left(l_{x+1} \cdot 1+l_{x+1} \cdot P\right)(1+i)-d_{x+1}}{l_{x+2}}$

Sehingga secara umum cadangan pada akhir tahun $t$ adalah $:{ }_{t} V=\frac{\left(l_{x+t-1} \cdot t-1\right.}{\left.V+l_{x+t-1} \cdot P\right)(1+i)-d_{x+t-1}}$ 


\section{Hasil dan Pembahasan}

\section{Contoh Penerapan}

Sebuah keluarga yang terdiri dari ayah usia 40 tahun, ibu usia 36 tahun, dan 1 anak laki-laki usia 9 tahun membeli polis asuransi kesehatan selama 10 tahun dengan santunan Rp. 200.000,- per hari untuk biaya kamar dan Rp. 75.000,- per hari untuk biaya kunjungan dokter maksimal 180 hari serta Rp. 4.000.000,untuk biaya perawatan per periode per tahun (Allianz Indonesia dalam Rizkiani. W, 2017).

Berdasarkan contoh penerapan maka akan dilakukan perhitungan premi tahunan bersih asuransi kesehatan individu perawatan rumah sakit dan cadangan premi asuransi kesehatan individu perawatan rumah sakit menggunakan metode retrospektif.

Perhitungan premi tahunan bersih asuransi kesehatan individu perawatan rumah sakit.

a. Perhitungan premi tahunan asuransi kesehatan individu perawatan rumah sakit jika preminya tidak diperbaharui, sebagai berikut :

- Ayah, usia 40 tahun :

$$
\begin{aligned}
P= & \frac{T^{s h} \sum_{t=0}^{9} \bar{D}_{40+t} q_{40+t}^{s h}}{N_{40}-N_{50}} \\
= & \frac{T^{s h}\left(\bar{D}_{40} q_{40}^{s h}+\bar{D}_{41} q_{41}^{s h}+\ldots+\bar{D}_{49} q_{49}^{s h}\right)}{N_{40}-N_{50}} \\
& =\frac{(((200.000+75.000) \times 180)+4.000 .000][(324.946,8054 \times 0,00618)+}{6.708 .572,66-3.849 .487,58} \\
= & 441.890,528 \approx \text { Rp. } 441.891,-
\end{aligned}
$$

- Ibu, usia 36 tahun :

$$
\begin{aligned}
P= & \frac{T^{s h} \sum_{t=0}^{9} \bar{D}_{36+t} q_{36+t}^{s h}}{N_{36}-N_{46}} \\
= & \frac{T^{s h}\left(\bar{D}_{36} q_{36}^{s h}+\bar{D}_{37} q_{37}^{s h}+\ldots+\bar{D}_{45} q_{45}^{s h}\right)}{N_{36}-N_{46}} \\
= & \left.\left.\frac{(((200.000+75.000) \times 180)+4.000 .000][(366.416,170 \times 0,00486)+}{8.128 .447,43-4.881 .357,04}, 695 \times 0,00515\right)+\ldots+(277.195,401 \times 0,001145)\right] \\
= & 339.191,472 \approx \text { Rp. 339.192,- }
\end{aligned}
$$


- Anak laki-laki, usia 9 tahun :

$$
\begin{aligned}
P= & \frac{T^{s h} \sum_{t=0}^{9} \bar{D}_{9+t} q_{9+t}^{s h}}{N_{9}-N_{19}} \\
= & \frac{T^{s h}\left(\bar{D}_{9} q_{9}^{s h}+\bar{D}_{10} q_{10}^{s h}+\ldots+\bar{D}_{18} q_{18}^{s h}\right)}{N_{9}-N_{19}} \\
& {[((200.000+75.000) \times 180)+4.000 .000][(770.236,013 \times 0,00212)+} \\
= & \frac{(749.856,388 \times 0,00197)+\ldots+(605.396,678 \times 0,0023)]}{23.275 .899,11-16.340 .808,38} \\
= & 109.834,411 \approx \text { Rp. } 109.835,-
\end{aligned}
$$

Jadi, premi bersih tahunan asuransi kesehatan individu perawatan rumah sakit untuk keluarga tersebut sebagai berikut :

Rp. 441.891,- + Rp. 339.192,- +Rp. 109.835,- = Rp. 890.918,-

b. Perhitungan premi tahunan asuransi kesehatan individu perawatan rumah sakit jika preminya diperbaharui dengan menggunakan persamaan (2.2.12), sebagai berikut :

- Ayah, usia 40 tahun :

Tahun ke-1, usia 40 tahun :

$$
\begin{aligned}
P & =\frac{T^{\text {sh }} \bar{D}_{40} q_{40}^{\text {sh }}}{N_{40}-N_{41}} \\
& =\frac{[((200.000+75.000) \times 180)+4.000 .000] \times[324.946,8504 \times 0,00618]}{6.708 .572,66-6.379 .589,04} \\
& =326.573,03 \approx \text { Rp. } 326.573,-
\end{aligned}
$$

Tahun ke-2, usia 41 tahun :

$$
\begin{aligned}
P & =\frac{T^{s h} \bar{D}_{41} q_{41}^{s h}}{N_{41}-N_{42}} \\
& =\frac{[((200.000+75.000) \times 180)+4.000 .000] \times[315.062,1449 \times 0,00659]}{6.379 .589,04-6.060 .612,93} \\
& =348.238,89 \approx \text { Rp. } 348.239,-
\end{aligned}
$$

Dengan persamaan yang sama akan dilanjutkan pada tahun ke-10.

Tahun ke-10, usia 49 tahun :

$$
\begin{aligned}
P & =\frac{T^{s h} \bar{D}_{49} q_{49}^{s h}}{N_{49}-N_{50}} \\
& =\frac{[((200.000+75.000) \times 180)+4.000 .000] \times[241.622,3686 \times 0,01145]}{4.094 .111,59-3.849 .487,58} \\
& =605.058,44 \approx \text { Rp. } 605.059,-
\end{aligned}
$$


- Ibu, usia 36 tahun :

Tahun ke-1, usia 36 tahun :

$$
\begin{aligned}
P & =\frac{T^{s h} \bar{D}_{36} q_{36}^{s h}}{N_{36}-N_{37}} \\
& =\frac{[((200.000+75.000) \times 180)+4.000 .000] \times[366.416,17 \times 0,00486]}{8.128 .447,43-7.757 .479,33} \\
& =256.819,57 \approx \text { Rp. } 256.820,-
\end{aligned}
$$

Tahun ke-2, usia 37 tahun :

$$
\begin{aligned}
P & =\frac{T^{\text {sh }} \bar{D}_{37} q_{37}^{\text {sh }}}{N_{37}-N_{38}} \\
& =\frac{[((200.000+75.000) \times 180)+4.000 .000] \times[355.741,695 \times 0,00515]}{7.757 .479,33-7.397 .318,32} \\
& =272.144,2 \approx \text { Rp. } 272.145,-
\end{aligned}
$$

Dengan persamaan yang sama akan dilanjutkan pada tahun ke-10.

Tahun ke-10, usia 45 tahun :

$$
\begin{aligned}
P & =\frac{T^{s h} \bar{D}_{45} q_{45}^{s h}}{N_{45}-N_{46}} \\
& =\frac{[((200.000+75.000) \times 180)+4.000 .000] \times[277.195,401 \times 0,00861]}{5.161 .996,00-4.881 .357,04} \\
& =454.982,81 \approx \text { Rp. } 454.983,-
\end{aligned}
$$

- Anak laki-laki, usia 9 tahun :

Tahun ke-1, usia 9 tahun :

$$
\begin{aligned}
P & =\frac{T^{s h} \bar{D}_{9} q_{9}^{s h}}{N_{9}-N_{10}} \\
& =\frac{[((200.000+75.000) \times 180)+4.000 .000] \times[770.236,013 \times 0,00212]}{23.275 .899,11-22.496 .094,59} \\
& =112.028,3 \approx \text { Rp. } 112.029,-
\end{aligned}
$$

Tahun ke-2, usia 10 tahun :

$$
\begin{aligned}
P & =\frac{T^{\text {sh }} \bar{D}_{10} q_{10}^{\text {sh }}}{N_{10}-N_{11}} \\
& =\frac{[((200.000+75.000) \times 180)+4.000 .000] \times[749.856,388 \times 0,00197]}{22.496 .094,59-21.736 .922,85} \\
& =104.101,8 \approx \text { Rp. } 104.102,-
\end{aligned}
$$


Dengan persamaan yang sama akan dilanjutkan pada tahun ke-10.

Tahun ke-10, usia 18 tahun :

$$
\begin{aligned}
P & =\frac{T^{\text {sh }} \bar{D}_{18} q_{18}^{\text {sh }}}{N_{18}-N_{19}} \\
& =\frac{[((200.000+75.000) \times 180)+4.000 .000] \times[605.396,678 \times 0,0023]}{16.953 .725,8-16.340 .808,38} \\
& =121.540,1 \approx \text { Rp. } 121.541,-
\end{aligned}
$$

Premi bersih tahunan asuransi kesehatan individu perawatan rumah sakit untuk ayah, ibu dan anak yang diperbaharui setiap tahun selengkapnya dapat dilihat pada Tabel 1.

Tabel 1. Premi bersih tahunan ayah, ibu dan anak diperbaharui setiap tahun

\begin{tabular}{|c|c|c|c|c|}
\hline Tahun & Ayah & Ibu & Anak & Total \\
\hline 1 & 326.573 & 256.820 & 112.029 & 695.422 \\
\hline 2 & 348.239 & 272.145 & 104.102 & 724.486 \\
\hline 3 & 371.490 & 288.526 & 100.932 & 760.948 \\
\hline 4 & 396.855 & 307.021 & 101.460 & 805.336 \\
\hline 5 & 424.862 & 326.573 & 104.631 & 856.066 \\
\hline 6 & 454.983 & 348.239 & 109.387 & 912.609 \\
\hline 7 & 487.746 & 371.490 & 113.614 & 972.850 \\
\hline 8 & 523.680 & 396.855 & 115.728 & 1.036 .263 \\
\hline 9 & 562.256 & 424.862 & 118.898 & 1.106 .016 \\
\hline 10 & 605.059 & 454.983 & 121.541 & 1.181 .583 \\
\hline
\end{tabular}

Berdasarkan perhitungan dan hasil pada Tabel 1, maka diperoleh premi tahunan yang diperbaharui setiap tahunnya semakin meningkat dan dibayarkan dalam rentang Rp. 695.422,- sampai Rp. 1.181.583,-

Perhitungan cadangan premi asuransi kesehatan individu perawatan rumah sakit dengan menggunakan metode retrospektif.

- Ayah, tahun ke-1 usia 40 tahun :

$$
\begin{aligned}
{ }_{1} V & =\frac{l_{40} \cdot P(1+i)-d_{40}}{l_{41}} \\
& =\frac{(883342 \times 441.890,5284)(1,025)-5459}{877883} \\
& =455.754,3195 \approx \text { Rp. 455.755,- }
\end{aligned}
$$

- Ibu, Tahun ke-1 usia 36 tahun :

$$
\begin{aligned}
{ }_{1} V & =\frac{l_{36} \cdot P(1+i)-d_{36}}{l_{37}} \\
& =\frac{(902.393 \times 339.191,4715)(1,025)-4386}{898.007} \\
& =349.369,3317 \approx \text { Rp. } 349.370,-
\end{aligned}
$$

- Anak, tahun ke-1 usia 9 tahun : 


$$
\begin{aligned}
{ }_{1} V & =\frac{l_{9} \cdot P(1+i)-1 . d_{9}}{l_{10}} \\
& =\frac{(973.869 \times 109.834,4106)(1,025)-2065}{971.804} \\
& =112.819,4922 \approx \text { Rp. } 112.820,-
\end{aligned}
$$

Cadangan premi tahunan asuransi kesehatan individu perawatan rumah sakit untuk ayah, ibu dan anak setiap tahun selengkapnya dapat dilihat pada Tabel 2.

Tabel 2. Cadangan premi ayah, ibu dan anak selama 10 tahun

\begin{tabular}{|c|c|c|c|}
\hline Tahun & Ayah & Ibu & Anak \\
\hline 1 & 455.755 & 349.370 & 112.820 \\
\hline 2 & 926.190 & 709.429 & 228.671 \\
\hline 3 & 1.412 .210 & 1.080 .737 & 347.632 \\
\hline 4 & 1.914 .833 & 1.463 .932 & 469.805 \\
\hline 5 & 2.435 .220 & 1.859 .694 & 595.309 \\
\hline 6 & 2.974 .649 & 2.268 .808 & 724.271 \\
\hline 7 & 3.534 .575 & 2.692 .126 & 856.801 \\
\hline 8 & 4.116 .675 & 3.130 .610 & 992.976 \\
\hline 9 & 4.722 .781 & 3.585 .372 & 1.132 .930 \\
\hline 10 & 5.355 .102 & 4.057 .612 & 1.276 .770 \\
\hline
\end{tabular}

Berdasarkan perhitungan dan hasil pada Tabel 2, maka diperoleh cadangan premi tahunan yang diperbaharui setiap tahunnya semakin meningkat dan dalam rentang masing-masing pada ayah Rp. 455.755,- sampai Rp. 5.355.102,- , pada ibu Rp. 349.370,- sampai Rp.4.057.612,- dan pada anak Rp. 112.820,- sampai Rp. 1.276.770,--

\section{Kesimpulan}

Berdasarkan hasil dan pembahasan maka dapat disimpulkan beberapa hal sebagai berikut:

1. Besar premi tahunan yang harus dibayarkan oleh ayah, ibu dan anak setiap tahunnya selama 10 tahun untuk premi yang tidak diperbaharui adalah Rp. 890.918,- dan untuk premi yang diperbaharui dibayarkan dalam rentan Rp. 695.422,- pada akhir tahun pertama sampai Rp. 1.181.583,- pada akhir ahun ke-10. Besar premi yang dibayarkan untuk premi yang diperbaharui akan terus meningkat dan cenderung lebih mahal dari premi yang tidak diperbaharui hingga pada akhir tahun ke-10.

2. Besar nilai cadangan premi tahunan asuransi kesehatan individu perawatan rumah sakit dengan menggunakan perhitungan cadangan retrospektif mengalami peningkatan setiap tahunnya hingga pada akhir tahun ke-10 untuk ayah (x) 40 tahun, ibu (x) 36 tahun dan anak ( $x$ ) 9 tahun masingmasing sebesar Rp. 5.355.102,-; Rp. 4.057.611,- dan Rp. 1.276.767,--

\section{Daftar Pustaka}

[1] Ali, A. Hasyim., Bidang Usaha Asuransi, Bumi Aksara, Jakarta, 1999.

[2] Futami, Takashi., Matematika Asuransi Jiwa, Bagian I. Terj. dari Seimei Hoken Sugaku, Jokan ("92 Revision), oleh Herliyanto, Gatot. Penerbit Incorporated Foundation Oriental Life Insurance Cultural Development Center, Japan, 1993.

[3] Destriani, Satyahadewi, N. \& Mara, M.N., Penentuan Nilai Cadangan Prospektif pada Asuransi Jiwa Seumur Hidup Menggunakan Metode New Jersey. Buletin Ilmiah Mat.Stat dan Terapannya (BIMASTER), 03, pp.7-12, 2014.

[4] Sembiring, R.K., Buku Materi Pokok Asuransi I, Modul I. Penerbit Karunika Jakarta Universitas Terbuka, 1996. 
[5] Workman, L.C., Mathematical Foundations of Life Insurance, 1994.

[6] Wilandari, Y., Asuransi Kesehatan Individu Perawatan Rumah Sakit. Jurnal Matematika, 73-78., 2007 